\title{
EDUCAÇÃO PATRIMONIAL E REELABORAÇÃO SIMBÓLICA EM PROCESSOS DE PATRIMONIALIZAÇÃ O CULTURAL: A SITUAÇÃO DE ANTÔNIO PRẢDO, RS
}

\author{
HERITAGE EDUCATION AND SYMBOLIC REVISION \\ IN CULTURAL PATRIMONIALIZATION PROCESSES: \\ THE SITUATION OF ANTÔNIO PRADO, RS
}

DOI: http//dx.doi.org/10.15448/2178-3748.2017.1.21841

Rodrigo Manoel Dias da Silva

Professor do Programa de Pós-Graduação em Educação da UNISINOS

rodrigoddsilva@hotmail.com

Gabriel Claro da Rosa

Professor Substituto no Instituto Federal de Educação, Ciência e Tecnologia do Rio Grande

do Sul - Campus Sertão

gabrielcdarosa@gmail.com

\begin{abstract}
RESUMO: O artigo pretende elaborar um diagnóstico sociológico sobre os usos da cultura e da patrimonialização cultural na sociedade contemporânea. A partir de estudo teórico e de uma análise situacional, almeja discutir as relações entre educação patrimonial, processos identitários e reelaboração das demarcações simbólicas tomando como elemento reflexivo a situação do tombamento histórico realizado em Antônio Prado, RS, no final da década de 1980, e seus desdobramentos pedagógicos e sociais na atualidade.
\end{abstract}

PALAVRAS-CHAVE: Educação patrimonial. Patrimonialização. Identidade.

ABSTRACT: The article intends to develop a sociological diagnosis on the uses of the culture and cultural patrimonialization in contemporary society. From theoretical study and of a situational analysis, aims to discuss relations between heritage education, identity and redesigning processes of symbolic demarcations on the reflective element the tipping situation history held in Antônio Prado, RS, in the late 1980, and its educational and social developments today.

KEYWORDS: Heritage education. Patrimonialization. Identity. 


\section{Primeiras palavras}

Os processos de patrimonialização cultural são processos tipicamente modernos. Tal associação justifica-se pela invenção moderna de um sentido específico de patrimônio, na esteira das definições de nacionalismo, de identidade nacional e das demarcações simbólicas que estabeleciam as fronteiras entre as produções identitárias e os valores coletivos nacionais. A patrimonialização, portanto, consiste em uma complexa operação seletiva que visa definir um conjunto de objetos, bens ou práticas representativos de uma determinada coletividade.

$\mathrm{Na}$ experiência dos nascentes Estados nacionais europeus, significava a identificação, valoração, proteção e difusão de princípios e valores de interesse nacional. As produções identitárias forjavam a produção de cidadãos, mediante programas de escolarização, criação de museus e "lugares da memória" (NORA, 1993). Nos termos de Michael Pollak (1989), houve um enquadramento das memórias, oficializando-as, em detrimento das "memórias subterrâneas", oriundas das culturas populares, dos grupos subalternos e socialmente inferiorizados.Assim,

Podemos, pois, falar em processos de patrimonialização como um movimento próprio do Ocidente moderno, com a criação de agências nacionais e internacionais a formação de agentes, a definição de políticas públicas. Trata-se de um campo com muitas disputas e um circuito próprio de circulação de ideias, práticas, artefatos, profissionais (ABREU, 2015, p. 69).

A partir de experiências muito variadas, que se expandiram para além da Europa, a antropóloga Regina Abreu sintetiza a trajetória dos processos de patrimonialização em três grandes momentos. No primeiro, do século XIX às primeiras décadas do século XX, "os processos de patrimonialização fundamentavam-se na reconstrução do passado (história) ou na busca e valorização de uma arte nacional" (ABREU, 2015, p. 69). Corresponde a este momento a constituição de organismos ou instituições de proteção do patrimônio nacional de diversos países, caso do Serviço do Patrimônio Histórico e Artístico Nacional (SPHAN), criado no Brasil na década de 1930. O segundo momento refere-se à criação da Unesco em 1946, a qual passa a intervir sistematicamente nos debates internacionais sobre cultura, advogando em nome de uma "concepção antropológica de cultura", moldando um importante campo de influência aos processos de patrimonialização.O terceiro momento,

Tem início no final dos anos de 1980, particularmente com o lançamento pela Unesco da Recomendação de Salvaguarda das Culturas Tradicionais e Populares em 1989, quando as políticas preservacionistas passam a ser normatizadas por fóruns internacionais, com a predominância da Unesco, 
estimulando uma dinâmica globalizada de identificação, proteção, difusão e circulação de valores e signos patrimoniais (ABREU, 2015, p. 69).

E ainda observa a autora:

É neste período que se implanta o que estou chamando de tendência à "patrimonialização das diferenças", em que a palavra de ordem, capitaneada sobretudo pela Unesco, é que "num mundo com tendência crescente à homogeneização" protagonizada pelo capitalismo globalizado e neoliberal, é preciso reverter, ou seja: conceder especial atenção à noção de singularidade ou de especificidade local (ABREU, 2015, p. 69).

Neste contexto, há uma ampliação dos processos de patrimonialização, visto a influência da concepção antropológica de cultura - cultura como modo de vida e experiência simbólica -, bem como a formulação de novos objetivos sociais para os projetos culturais na contemporaneidade. No caso brasileiro, os referidos processos adquiriram novo dinamismo e segmentos populacionais antes silenciados ou ausentes nas políticas patrimoniais passam a reivindicar tombamento, registro ou reconhecimento oficial. As definições de patrimônio se ampliam, incorporando patrimônios tangíveis e intangíveis, paisagísticos e ambientais, mediados por tecnologias e outras ferramentas de registro das manifestações culturais. $\mathrm{O}$ barroco e os bens edificados remanescentes da colonização lusitana passam a concorrer com múltiplas referências culturais e identitárias para a definição do patrimônio nacional.

Uma das primeiras experiências orientadas por tais concepções foi a patrimonialização do casario colonial no município de Antônio Prado, na Serra Gaúcha, primeiro tombamento de bens remanescentes da imigração italiana no Brasil. A cultura popular dos imigrantes italianos no Sul do país tornou-se patrimônio nacional. Como já relatado em outros estudos (LEWGOY, 1997; ROVEDA, 2005; BUCHEBUAN, 2010; SILVA, 2013), o processo foi marcado por inúmeros tensionamentos e reações, configurando condições favoráveis para a emergência da educação patrimonial como meio de "reconciliação da população com suas memórias" (MEMÓRIA E PRESERVAÇÃO, 2009). Ao mesmo tempo, tal patrimonialização engendrou novos agenciamentos culturais voltados a novos objetivos sociais, como a ativação de interesses econômicos e turísticos no lugar, mas também de uma reelaboração simbólica a partir da educação patrimonial.

O propósito deste estudo consiste na elaboração de um diagnóstico sociológico sobre os usos da cultura e da patrimonialização cultural na sociedade contemporânea. A partir de estudo teórico e de uma análise situacional, almeja discutir as relações entre educação patrimonial, processos identitários e reelaboração das demarcações simbólicas tomando como 
elemento reflexivo a situação do tombamento histórico realizado em Antônio Prado, RS, no final da década de 1980, e seus desdobramentos pedagógicos e sociais na atualidade.

\section{Cultura, processos culturais e rendimento monopólico: elementos para um diagnóstico sociológico}

Diversas elaborações contemporâneas têm enfatizado um deslocamento nos sentidos atribuídos à cultura e a seus múltiplos processos e práticas sociais (FEATHESTONE, 1997; YÚDICE, 2002; MARTÍN-BARBERO, 2004; CANCLINI, 2006; LIPOVETSKY, SERROY, 2011; SOVIK, 2014). De certo modo, é possível considerarmos que a cultura, historicamente situada no plano transcendental, toma parte na imanência, na experiência concreta da vida humana em sociedade e passa a ser agenciada por novos objetivos e projetos sociais. Neste contexto, Mike Featherstone mencionou que "a cultura já não pode mais proporcionar uma explicação adequada ao mundo que nos permita construir ou ordenar nossas vidas" (1997, p. $15)$.

Tal deslocamento contextualiza-se diante das transformações operadas pela globalização da economia, pelos massivos processos migratórios e suas alterações demográficas, pelos novos contornos da construção das políticas de Estado e da ação estatal, pelas inovações tecnológicas, pelas telecomunicações, pela indústria do turismo e do entretenimento e pela constante "capitalização do simbólico" (YÚDICE, 2002). A cultura é interpretada como "reserva disponível" para projetos e políticas de diversas origens (YÚDICE, 2004), cujas estratégias de ação são direcionadas por complexas finalidades.

A cultura torna-se um recurso (YÚDICE, 2002; 2004). Projetos sociais, projetos de enfrentamento da pobreza, de salvaguarda dos patrimônios, de revitalização de áreas urbanas, de desenvolvimento socioeconômico, de educação ou de turismo incorporam esta dimensão imanente da cultura e passam a agenciá-la. De dimensão contemplativa e ideologicamente superior, próprios dos universos de uma suposta cultura de elite, tal noção constrói-se desde novos "mandatos performativos" (YÚDICE, 2002). Na sequência deste diagnóstico, será objeto de análise a contribuição de três destacados intelectuais engajados na compreensão dos fenômenos culturais, à luz das transformações econômicas transcorridas na atualidade, a saber: George Yúdice, David Harvey e Jesús Martín-Barbero.

Para George Yúdice, a cultura perfaz transversalmente os aspectos mais dinâmicos da vida contemporânea. De capital simbólico a elemento fundamental da economia de mercado, 
a cultura plasma um campo de forças performativas, de disputas e de contingências observadas na cidadania e no consumo, entrementes posicionada em uma dimensão política.

Poderíamos elaborar este fator político como um campo de forças definidas pela inserção na economia mundial, o desenvolvimento tecnológico, a especificidade da indústria particular, as demandas das elites nacionais, as necessidades dos cidadãos e a particular maneira em que estas necessidades se transmutam na demanda de consumidores (YÚDICE, 2002, p. 20 [tradução nossa]).

A cultura, portanto, contextualiza-se no âmbito da transnacionalização da economia, onde os "processos de formação de identidades culturais obedecem a mandatos performativos" (YÚDICE, 2002, p. 22). Dito de outra forma, as manifestações culturais não podem ser pensadas fora de seu contexto, do qual deriva seu valor. Neste sentido, tais manifestações se constituem dentro dos processos de globalização, em seus fluxos e trocas econômicas, bem como nas redefinições sociais e territoriais de escala local e global. De modo complementar, Liv Sovik observa que estas dinâmicas culturais tomam distintas feições na sociedade brasileira, sendo que suas aproximações a projetos sociais assumem uma posição privilegiada. Segundo a autora, a fundação do Olodum, em 1979, marca "o início da atual onda, na cena cultural urbana, de projetos culturais, de arte-educação ou socioeducativos, cuja missão é a de orientar setores jovens da população pobre do Brasil para a conquista da cidade, usando a cultura como ferramenta de educação para a transformação social" (SOVIK, 2014, p. 172-173). A cultura é agenciada como ferramenta de cidadania, ora tornando evidentes engajamentos em projetos orientados para o enfrentamento da desigualdade estruturante presente na sociedade brasileira, ora articulada à formação de talentos para iniciativas culturais vinculadas a circuitos econômicos específicos (SILVA, 2014).

David Harvey (2012), por sua vez, constata que a cultura inegavelmente se tornou uma mercadoria. Para explicar a relação entre cultura e mercadoria o autor se utiliza do conceito de "rendimento monopólico", a partir da constatação de que determinados bens se inscrevem em fluxos de trocas econômicas ampliadas globalmente, porém determinados grupos exercem controle privilegiado sobre seus rendimentos. Refere-se à comercialização de bens entendidos como únicos, específicos ou não-duplicáveis, o que, sendo Harvey, é o caso das produções culturais.

Há duas situações nas quais a categoria rendimento monopólico vem à frente. A primeira surge porque os atores sociais controlam algum recurso, mercadoria ou lugar de qualidade especial que, em relação a certo tipo de atividade, lhes permite extrair rendimentos monopólicos daqueles que desejam usá-lo. No reino da produção, argumenta Marx, o exemplo mais 
óbvio é o vinhedo que produz vinho de qualidade extraordinária, que pode ser vendido a preço monopólico (HARVEY, 2012, p. 141).

Nestas situações, produz-se renda indiretamente, pois é o preço do monopólio que cria a renda, lembra-nos Harvey. Este parece ser o caso da hotelaria, do turismo e do artesanato. Há, contudo, situações onde o conteúdo cultural atribui diretamente valor ao bem.

No segundo caso, a terra ou recurso é diretamente comercializado (como quando os vinhedos ou terrenos de primeira linha são vendidos a capitalistas e financistas multinacionais com propósitos especulativos). A escassez pode ser criada retirando-se a terra ou o recurso dos usos correntes e especulando com valores futuros (HARVEY, 2012, p. 142).

Em muitas circunstâncias, as duas formas de rendimento se mesclam. Estas categorias de rendimento apresentam contradições. A primeira: embora todo bem cultural se constitua a partir de suas singularidades e particularidades, características fundamentais para sua diferenciação, a exigência de valor comercial exige que no limite sejam considerados como mercadorias simples para fins de cálculo monetário. Essa relação é determinante para a definição do valor monopólico. Tomemos, como exemplo, produções artesanais em quaisquer regiões do Brasil, quanto mais exclusivo e "especial" for este artesanato, menor deve ser a quantidade de sua reprodução, para garantir sua diferenciação em relação às mercadorias em geral. Outra contradição: a definição de um bem cultural e a expectativa de rendimento monopólico não exclui a competição, a concorrência e as disputas no mercado. Para Harvey, neste sentido, a cultura, a memória e o patrimônio são produções culturais preciosas nas disputas econômicas entre as cidades contemporâneas, pois, utilizando-se dos termos de Pierre Bourdieu, “o que está em jogo é o poder do capital simbólico coletivo, de marcas especiais de distinção que se apegam a algum lugar que tenha um poder de atração significativo sobre os fluxos do capital em termos gerais" (HARVEY, 2012, p. 158).

Jesús Martín-Barbero, em outra perspectiva, argumenta que para compreendermos a cultura e os processos culturais hodiernos precisamos repensá-los a partir das novas referências presentes nas dinâmicas culturais e, particularmente, naquelas que se referem à cultura de massa. Segundo o autor, as relações entre educação, cultura e comunicação de massa, principalmente entre as camadas mais jovens da população, engendram novas demarcações simbólicas. Três destas dinâmicas são destacadas:

A primeira concerne ao modo como as indústrias culturais estão reorganizando as identidades coletivas, as formas de diferenciação simbólica, ao produzir hibridações novas que deixam caducas as 
demarcações entre o culto e o popular, o tradicional e o moderno, o próprio e o alheio (MARTÍN-BARBERO, 2004, p. 151).

Pensar os processos culturais exige a compreensão das demarcações simbólicas produzidas e suas relações com as identidades coletivas. Uma segunda dinâmica sinaliza para a seleção dos processos informacionais pelos quais as culturas reelaboram-se. "Ora, ao mesmo tempo em que os meios maciços misturam, hibridizam, eles também superam, quer dizer, aprofundam e reforçam as divisões sociais, refazem as exclusões que vêm da estrutura social e política, legitimando-as culturalmente" (MARTÍN-BARBERO, 2004, p. 152).

Um terceiro tipo de dinâmica, vigente entre os meios maciços de comunicação, é o advento de culturas ou subculturas não ligadas à memória tradicional, a partir da criação de novas comunidades culturais, da fabricação de novos processos identitários, com diversas temporalidades e ancoragens geográficas.

Trata-se não só de culturas novas mas das culturas de que vivem os jovens, e que por não ter uma âncora geográfica definida são com frequência apontadas como antinacionais, quando na verdade nos estão apontando é a existência de novos modos de operar e perceber a identidade" (MARTÍNBARBERO, 2004, p. 153).

A produção de estudos sobre os processos de patrimonialização cultural, na atualidade, exige a elaboração de um diagnóstico sociológico sobre a condição dos próprios processos culturais, os múltiplos usos da cultura e suas implicações com outras dimensões da vida social. No entanto, tais abordagens precisam considerar as múltiplas mediações destes fenômenos em contextos locais, em perspectiva situacional. Este será o mote da sequência deste artigo.

\section{O tombamento histórico em Antônio Prado: descrevendo uma situação}

O município de Antônio Prado está localizado na região nordeste do Rio Grande do Sul, na Serra Gaúcha, distante aproximadamente 180 quilômetros de Porto Alegre. Inicialmente habitada por indígenas 'tape' e 'coroado', a região foi aos poucos povoada por fazendeiros de Vacaria, na próxima região dos Campos de Cima da Serra, que eram de origem lusa e dedicavam-se à produção agropecuária em latifúndios. Muitos destes eram "provenientes de São Vicente e Laguna" e chegaram às terras do local "pelo antigo litígio entre Espanha e Portugal" (GIRON, 2001). Em 1875, chegaram ao Estado os imigrantes italianos, sendo que Antônio Prado foi a sexta e última das "antigas colônias de imigração 
italiana ${ }^{1}$ ", fundada em 1886. Com a nova colônia, diversas obras públicas foram sendo desenvolvidas com a finalidade de melhorar o acesso à cidade, a qual estava em região geográfica de difícil acesso, em meio à serra do Rio das Antas. Nestas condições, os imigrantes derrubaram matas e construíram suas casas com a madeira disponível no lugar, pedras e tijolos artesanais ${ }^{2}$ (MEMÓRIA E PRESERVAÇÃO, 2009, p. 7).

No início do século XX, a cidade representou importante centro do comércio regional. Roveda (2005) observa que, no período, chegou-se a registrar duas dezenas de casas comerciais, que, inclusive, serviam aos municípios vizinhos. Além de referência no ciclo econômico regional de exploração da madeira (araucária), passava pelo interior do município a estrada Júlio de Castilhos - importante ligação entre diversas regiões do Estado -, o que facilitava suas transações comerciais com as cidades vizinhas. Porém, a construção da BR 116, em 1930, progressivamente afastou a dinâmica da economia para Caxias do Sul, favorecendo uma relativa situação de isolamento até meados dos anos de 1980.

Esse relativo isolamento colaborou para a conservação de uma nucleação urbana, tendo em vista a permanência histórica do casario remanescente dos tempos da imigração. Em 1985, Antônio Prado teve seu "primeiro imóvel representativo da arquitetura popular da imigração italiana tombado, denominado 'Casa da Neni" ${ }^{3, "}$ (ROVEDA, 2005, p. 59). Em torno da Praça Garibaldi, 48 edificações em madeira se encontravam em muito bom estado de conservação, formando um Centro Histórico que veio a ser tombado pelo IPHAN em 1987, com registro definitivo no Livro do Tombo Arqueológico, Etnográfico e Paisagístico e no Livro do Tombo Histórico, em 10 de janeiro de 1990. O acervo pradense representou importante marco nas políticas patrimoniais brasileiras, uma vez que foi o primeiro tombamento material que não havia originado de imigração portuguesa. Além da dimensão material, se encontram em Antônio Prado importantes traços da cultura tradicional dos imigrantes italianos, como a gastronomia, o artesanato, a linguagem (um exemplo é o "talian", dialeto híbrido usado pelos imigrantes e seus descendentes), os referentes do catolicismo popular e outras manifestações culturais.

Porém, o tombamento não foi bem aceito pela maioria da população, desencadeando uma série de tensionamentos e conflitualidades (BUCHEBUAN, 2010). Fernando Roveda menciona que "a ideia do tombamento do conjunto localizado no centro já havia provocado reação por parte de alguns proprietários de casas que já pensavam em demolir, como fizeram

\footnotetext{
${ }^{1}$ Informações completas disponíveis em: http://www.antonioprado.com.br/historico.php

${ }^{2}$ Para uma contextualização histórica da imigração italiana no Rio Grande do Sul, ver Giron e Herédia (2007).

${ }^{3}$ Registrado no Livro do Tombo de Belas Artes, sob o n 572, em 30 de setembro de 1985.
} 
com a Casa de Negócios Valmórbida, casa com mais de cem anos, demolida durante o processo $^{4 \%}$ (ROVEDA, 2005, p. 61). Após o início do processo de tombamento, em 1987, inúmeras foram as manifestações da população local rejeitando as ações do IPHAN na cidade. A imprensa tratava de veicular o impasse nas representações sociais sobre a patrimonialização, entre a estagnação e o progresso.

O jornal mensal Panorama Pradense foi um importante veículo de divulgação da controvérsia em torno do tombamento. Alguns artigos elogiavam a ação da SPHAN - que declarou Antônio Prado monumento nacional - ainda que com reservas em relação ao encaminhamento, tido como autoritário. Outros criticavam o tombamento alegando que prejudicaria o progresso da cidade, por opor barreiras ao crescimento e ocupação urbana. Também despontavam afirmações de que o problema não era o tombamento, mas sim as péssimas condições das estradas de acesso à cidade, ainda com trechos não-asfaltados à época. Havia, ainda, matérias que destacavam que finalmente o progresso viria a Antônio Prado, pelo incentivo ao turismo (LEWGOY, 1997, p. 6).

Além de sessões públicas na Câmara Municipal de Vereadores e pedidos de esclarecimentos aos setores governamentais diretamente vinculados ao patrimônio, criou-se a Associação Pradense de Defesa dos Direitos de Propriedade dos Imóveis, registrada oficialmente, cuja finalidade exposta em seu Estatuto Jurídico era:

[...] lutar, proteger e defender os interesses dos proprietários contra o tombamento e, de modo especial, acompanhar o respectivo processo do conjunto histórico, arquitetônico e paisagístico da cidade de Antônio Prado e entorno, e demais interesses de seus associados relativamente à propriedade de imóveis e direitos a eles relativos (apud ROVEDA, 2005, p. 66-67).

O objetivo da entidade era estagnar ou reverter o tombamento ou, em última instância, angariar uma indenização aos proprietários. Para atenuar a situação, inúmeras ações foram realizadas, tais como: a concessão, por parte do Poder Público Municipal, de isenção de impostos aos imóveis de conteúdo histórico ou cultural; a criação de uma fundação cultural; realização de campanhas com empresas e entidades comerciais para subsidiarem a reforma das casas. Muitas destas iniciativas não atingiram objetivos satisfatórios, tampouco a Associação conseguiu reverter o processo de tombamento. As funções da Associação se esgotaram, sobretudo, quando o governo Collor realizou o desmonte dos setores governamentais atuantes em cultura.

Desde a década de 1990, o órgão federal de patrimônio passou a contribuir no restauro das edificações. Além disso, para reconstruir a identidade e o pertencimento local, assim

\footnotetext{
${ }^{4}$ Essa demolição alterou a redação original da proposta de 48 para 47 edificações tombadas.
} 
como para a mediação dos conflitos, novas políticas patrimoniais passaram a ser implementadas no lugar. A política patrimonial converteu-se, primeiramente, em ações de educação patrimonial, a qual foi mobilizada no sentido de "ação intensiva" voltada à conscientização dos moradores, para a valorização do patrimônio, da memória e da cultura do lugar. Tais ações justificavam-se porque existiam diversas problematizações em relação à representatividade das casas enquanto elemento distintivo da memória local, se estas "representavam ou não a experiência de imigração e colonização italiana na região" (LEWGOY, 1997, p. 6).

Outras ações do IPHAN também foram realizadas com finalidade semelhante: a confecção de brinquedos para as crianças, quebra-cabeças com a imagem da "Casa da Neni" primeira casa tombada -, elementos da culinária local, além de uma cartilha de educação patrimonial usada nas escolas (MEMÓRIA E PRESERVAÇÃO, 2009, p. 33). Em parceria com a Universidade de Caxias do Sul, diversas outras iniciativas foram desenvolvidas. O fortalecimento dos vínculos de pertencimento local à cultura dos imigrantes italianos foi tema constante das atividades, inspirados, em boa medida, no filme "O Quatrilho", baseado no imaginário regional da imigração italiana e gravado na cidade e na região. Em semelhante perspectiva, o turismo cultural fez-se uma alternativa ao desenvolvimento da região, idealizado por diversas gestões municipais que se sucederam, bem como por instâncias regionais, cujo objetivo era a inserção da cidade em circuitos regionais do turismo. Então, o material publicitário da cidade foi reorientado e Antônio Prado tornou-se a "Cidade mais italiana do Brasil”, premissa reafirmada na distribuição de pequenas tabuletas com tal inscrição pelo centro histórico. Há novas demarcações simbólicas enfatizando novos processos identitários, ora evocando a identidade italiana da imigração, ora reivindicando representações do tombamento e da autodesignação "patrimônio histórico nacional”. De modo complementar,

\footnotetext{
Note-se que o tombamento introduziu todo um conjunto de normas e significações que repercutiram agudamente no cotidiano de Antônio Prado, atingindo desde as relações dos habitantes com o espaço urbano até a própria representação mais ampla a respeito da cidade em que vivem (LEWGOY, 1997, p. 7).
}

De certo modo, em Antônio Prado, a política patrimonial está atrelada a uma pedagogia da memória, onde os atores culturais e os agentes estatais assumem a tarefa

\footnotetext{
${ }^{5}$ Filme dirigido por Bruno Barreto, lançado em 1995, inspirado em obra homônima de autoria de José Clemente Pozenato.
} 
educativa de "reconciliação da população com suas memórias". Um relato do IPHAN, sobre o período, é ilustrativo:

Para reconciliar a população da cidade com sua herança histórica, o Iphan promoveu uma série de ações, dentre as quais a primeira ação intensiva de educação patrimonial realizada no país até aquele período. Vários recursos foram utilizados. O cartunista Iotti, hoje muito conhecido no estado, foi "importado" de Caxias do Sul para colaborar no esforço educativo. $\mathrm{Na}$ época, o cartunista estava em início de carreira e trabalhava em jornal caxiense. Seus personagens despediram-se da publicação informando aos leitores que pretendiam conhecer Antônio Prado. E se hospedaram durante um ano em página de um jornal pradense. Uma das figuras dos cartuns, o Nonno, aparecia falando taliancom pessoas da comunidade, inclusive com algumas que se opunham ao tombamento, sobretudo o que dizia respeito à vida na cidade (MEMÓRIA E PRESERVAÇÃO, 2009, p. 29).

Para a mediação dos conflitos entre os atores, a política patrimonial confundia-se com a educação patrimonial. De um lado, a inserção da temática na formação escolar dos estudantes mediante cartilhas e atividades lúdico-recreativas promovidas pelo IPHAN. De outro, ações para a "reconstrução de manifestações expressivas" do lugar (MARTINS, 2009), com foco na recuperação e uso social dos processos identitários dos antigos imigrantes, produzindo uma nova semântica para a patrimonialização no contexto da cidade. Os objetivos sociais das políticas patrimoniais, nesta situação, enfatizavam a produção de sentidos para o ato de tombamento do casario, mediante a valorização da regionalidade colonial e sua potencialização para projetos de desenvolvimento turístico.

O tombamento e a experiência de patrimonialização na cidade desencadeou a emergência de inúmeros projetos em educação patrimonial interessados em revelar e reconhecer as produções identitárias locais. Faremos, na próxima seção, uma análise situacional $^{6}$ dos projetos de educação patrimonial em desenvolvimento em Antônio Prado e suas relações com a atualidade do processo de patrimonialização cultural acima descrito.

\section{Educação patrimonial, cultura e identidade na "cidade mais italiana do Brasil"}

Em 1996, Fernando Roveda, pesquisador local, iniciou um levantamento sobre a história do conjunto arquitetônico e urbanístico de Antônio Prado. A recuperação da história

\footnotetext{
${ }^{6}$ Constitui um importante meio etnográfico de obter dados, analisar e interpretar a realidade social, porque, como considera as normas em conflito. Assim, os distintos pontos de vista dos atores sociais evocam uma análise sincrônica daqueles princípios estruturais, da mesma forma que uma análise diacrônica da operação destes princípios por atores em situações específicas (VAN VELSEN, 1987, p. 372). Enquanto coleta e análise de dados, a análise situacional permite a realização de busca de informações em diversas fontes, tanto quanto o uso de múltiplas técnicas.
} 
de cada casa tombada foi parcialmente retratada em livro (ROVEDA, 2005), mas também contribuiu para a formulação de subsídios para um projeto de intervenções em educação patrimonial. O objetivo do estudo, que foi desenvolvido ao longo de oito anos, foi o de demonstrar "a relevância da reconstituição da história local e da interpretação para a salvaguarda do patrimônio cultural, integrada a diretrizes de administração, visando a um desenvolvimento mais sustentável a partir de atividades do turismo cultural" (ROVEDA, 2005, p. 11).

A partir desta pesquisa, em 2004, iniciou o projeto "Memória e Identidade: Antônio Prado, Patrimônio Histórico e Artístico Nacional”, experiência apoiada pelo Programa Monumenta e um dos vencedores do Prêmio Rodrigo Melo Franco de Andrade (Ministério da Cultura, em 2005). A proposta envolveu a elaboração de seis atividades orientadas para uma interpretação do patrimônio tombado, tanto para estudantes das escolas locais, quanto para turistas que começavam a visitar o centro histórico, a saber: publicação de livro; guia de visitação (mapa); guia de visitação sonorizado; material audiovisual; placas informativas distribuídas pelo casario; e confecção de uma maquete da área tombada.

O projeto concebido a partir da constatação de que havia um desconhecimento da população em relação a suas memórias e, em alguma medida, da incapacidade dos moradores para falarem sobre sua cidade. Esse desconhecimento foi percebido pelo informante a partir da década de 1990 quando ocupou uma secretaria na Prefeitura Municipal, num contexto onde iniciavam as visitações ao tombamento. Quando interpelados por turistas, os moradores do lugar tinham poucas informações sobre a história e os sentidos de seu patrimônio. Em entrevista, Roveda sintetiza suas percepções daquele momento imediatamente posterior ao tombamento:

\begin{abstract}
A gente recebia os turistas aqui e eles vinham pra cá, vislumbravam a arquitetura que era diferente de outros lugares, outros centros contemporâneos na verdade, viam que a arquitetura era diferente e isso era o primeiro momento. No segundo momento, a história. Eles queriam saber quem construiu a casa, como é que foi, porque que era assim e tal. E eu, ouvindo isto, percebia que a gente não tinha resposta para estas perguntas (Fernando Roveda, pesquisador)
\end{abstract}

Nosso informante acrescenta que não se tratava apenas de desconhecimento, havia ainda muita rejeição ao tombamento. Considerando que o ato oficial havia ocorrido no final da década de 1980, constata que as primeiras ações de educação patrimonial desenvolvidas pelo IPHAN teriam sido insuficientes, principalmente porque as ações de educação patrimonial, bem como as políticas patrimoniais, sofriam pela descontinuidade. Neste sentido, 
decidiu promover ações em educação patrimonial de modo independente, recorrendo a editais públicos e a iniciativa privada para obtenção dos recursos financeiros necessários às mesmas.

Antônio Prado estava muito conflitado, ele não tinha, ainda hoje tem muito problemas, não tinha muitas saídas, então a saída maior era atuar nas bases com as crianças com a educação patrimonial. Para quê? Para começar a mudar a realidade de lá e não das pessoas que já são adultas, que não concordam, porque dificilmente você muda. Eu vou te dizer que a atuação nas bases com as escolas foi o ponto estratégico de resultado para o projeto (Fernando Roveda, pesquisador).

$\mathrm{O}$ argumento de Roveda retoma a ideia de que a educação patrimonial deveria reconciliar a população com suas memórias. Nesse trabalho de memória, o pesquisador local promoveu iniciativas orientadas para os moradores da cidade e outras a seus visitantes. Uma das ações desenvolvidas, como comentado acima, consistiu em uma pesquisa sobre as histórias de cada uma das casas tombadas, produzindo mapas, folhetos informativos, guias sonorizados e a inscrição de tabuletas com pequenas sínteses da história da edificação, em cada uma das casas. O conflito local e o desconhecimento sobre o passado do lugar seriam enfrentados com tais tabuletas, inscrevendo nos próprios imóveis as informações que os turistas esperavam encontrar. A Figura 1 exemplifica a construção deste material.

\section{Figura 1}

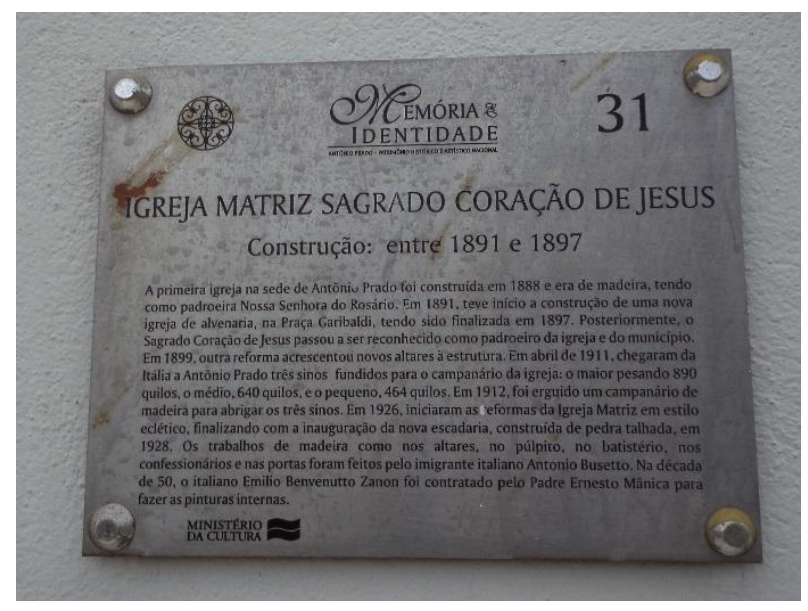

Fonte: Acervo da pesquisa

Outra ação desenvolvida foi a construção de uma maquete do centro histórico tombado. Instalada na Casa Grezzana - o sobrenome dos primeiros moradores das casas fizeram-se topônimos utilizados para localização na cidade - e aberta à visitação, a maquete foi inaugurada em 2008. Desde então, o espaço recebe grupos de estudantes, escolas, universidades e turistas. Ao mesmo tempo, a história de cada uma das casas foi narrada e gravada pelos estudantes das escolas do município, produzindo guias sonorizados oferecidos 
aos visitantes, mas também tornando estas histórias objeto de reflexão no cotidiano das escolas. A recomposição das memórias das casas foi produzida em diálogos com idosos e moradores mais antigos de Antônio Prado e o material produzido foi objeto de leitura e de gravação por estudantes das escolas do município. A ideia era dar voz às casas.Outro excerto da entrevista reforça esse argumento:

A comunidade ajudou a montar o quebra-cabeça de partes da memória de Antônio Prado, com a comunidade, as crianças trabalhariam as vozes das casas dando voz para a casa e ainda dando identidade para ela (Fernando Roveda, pesquisador).

O depoimento acima afirma que as ações de educação patrimonial precisariam atribuir sentido identitário ao tombamento material, evidenciando desencontros entre patrimônio e identidade. Como observa o sociólogo Paulo Peixoto, há uma relação ambígua entre patrimônio e identidade nos processos de patrimonialização cultural, tendo em vista que, hoje, o patrimônio "presta-se a acções pedagógicas, turísticas, políticas, econômicas e a experiências técnicas e sociais de ponta" (PEIXOTO, 2004, p. 184). Assim, a identidade converte-se em recurso retórico ou metonímico à patrimonialização, em uma nova sintaxe do espaço urbano ou de suas políticas.

Há casos, pois, em que os tombamentos ou registros oficiais demandam processos identitários que lhe justifiquem e lhe deem novos sentidos. Nos termos do sociólogo,

A refuncionalização do passado que as políticas urbanas promovem adquire formas diversas. Oscilando entre a reactivação, a reinvenção e a idealização, os processos de patrimonialização manifestam-se quando uma consciência patrimonial e o patrimônio substituem uma identidade vivida e partilhada, ou quando uma identidade é branqueada, depurada ou imaginada. Mas, o patrimônio não corresponde necessariamente à versão mais essencialista de uma identidade. [...] Acresce que a relação entre o estatuto puramente identitário e o puramente tradicional é com frequência conflitual, revelandose esse conflito na concretização dos processos de patrimonialização (PEIXOTO, 2005, p. 184-185).

Há, nos processos de patrimonialização cultural, uma reelaboração simbólica, a qual, no caso de Antônio Prado, organiza-se acerca da educação patrimonial. Por um lado, o projeto de Fernando Roveda engendra uma reelaboração simbólica a partir das experiências escolares. Uma terceira ação promovida pelo pesquisador local consiste em distribuir kits com maquetes impressas em papel ofício, estes são levados para casa pelos estudantes e trazidos à escola com unidades do casario montadas e coloridas. Pinte, cole e monte o patrimônio da cidade! A 
identificação com o casario colonial e com a imigração italiana no Sul do Brasil torna-se recurso metonímico (PEIXOTO, 2015) para a patrimonialização ocorrida em Antônio Prado.

Por outro lado, outra reelaboração simbólica refere-se aos aspectos econômicos do município. Há uma retomada da imigração italiana enquanto recurso retórico ao processo vivido em Antônio Prado, convertendo-a em "Cidade mais italiana do Brasil” (Figura 2). Esse conteúdo identitário tem se tornado recurso ao desenvolvimento turístico, como "reserva disponível" (YÚDICE, 2004) aos projetos socioeconômicos. Segundo o depoimento de Fernando Roveda, a dimensão econômica se torna uma questão imprescindível no contexto pós-tombamento.

\begin{abstract}
A história do lugar nos remete para um conflito no início de todo este patrimônio e o conflito tanto se dá na esfera da comunidade quanto na área da política. [...] As pessoas não aceitaram em tudo. Houve até uma criação de uma agência, uma associação para "destombar". [...] Então, tu tem que fazer uma relação de educação patrimonial com o turismo, isto está intimamente ligado, não tem como separar (Fernando Roveda, pesquisador).
\end{abstract}

Esta dimensão econômica é evidente nos eventos turísticos em desenvolvimento na cidade, que tomam a "italianidade" como recurso para atratividade turística e o centro histórico como paisagem privilegiada. Um destes eventos é a Fenamassa (Figura 3), evento turístico direcionado à divulgação da gastronomia local, a partir da ativação de elementos da memória local organizada pelos sentidos da imigração italiana, através da ideia de retorno às origens.

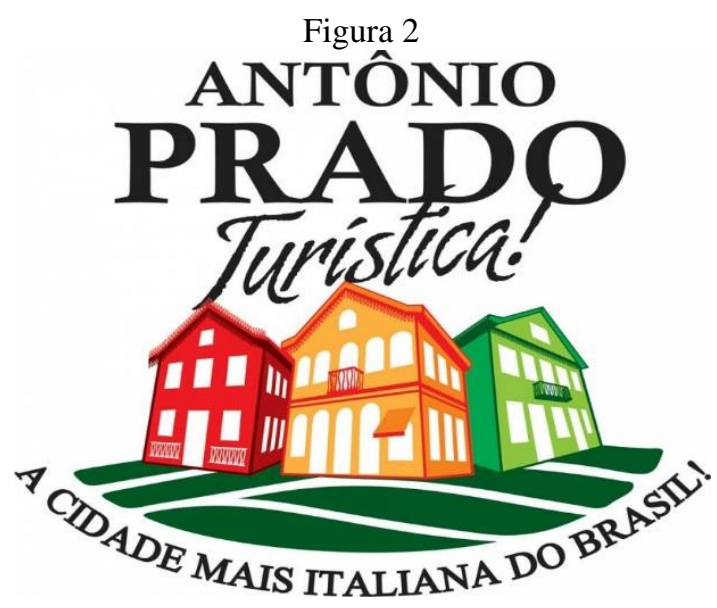

Fonte: Acervo da pesquisa

Figura 3 


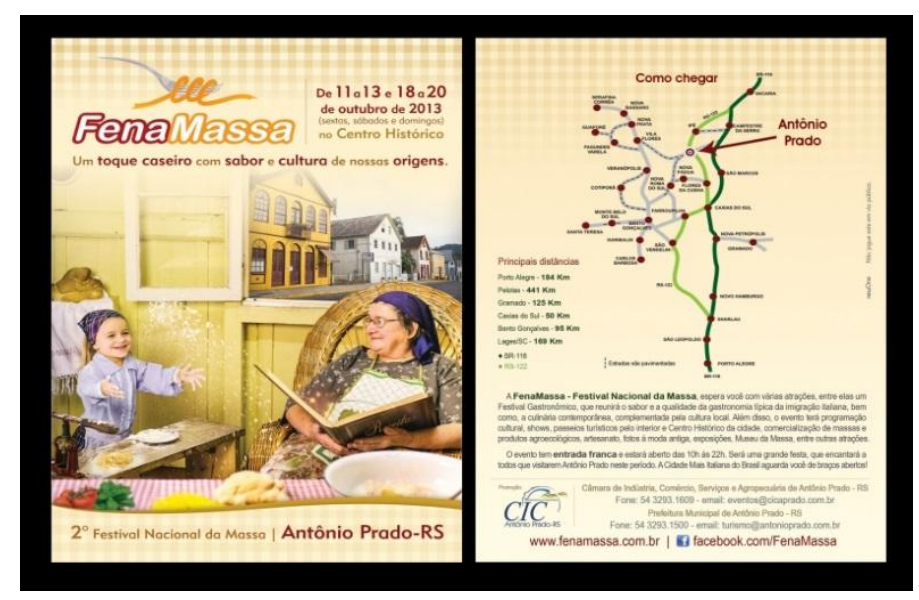

Fonte: Acervo da pesquisa

Outra iniciativa de educação patrimonial desenvolvida em Antônio Prado é o projeto "Pulando Janelas: educação turística, ambiental e patrimonial", desenvolvido por uma instância de governança regional, a Associação de Turismo da Serra Nordeste (Atuaserra). A ação, entre 2006 e 2009, foi desenvolvida em outros seis municípios da região serrana: Protásio Alves, Nova Prata, Vila Flores, Veranópolis, Fagundes Varela e Cotiporã. Desde 2010 em Antônio Prado, o projeto é realizado em uma parceria entre a Atuaserra, a Associação Comercial (CIC-Prado), as secretarias municipais de educação e de turismo e, a partir de 2015, conta com apoio financeiro do Banco do Estado do Rio Grande do Sul.De acordo com as informações institucionais da agência promotora, o projeto:

Trata da disseminação da educação patrimonial, ambiental e turística a crianças e adolescentes de escolas públicas e privadas da região. Através deste projeto planeja-se a preparação e difusão de informações para crianças, jovens e adolescentes sobre a questão turística, com a perspectiva de que, no futuro, o segmento do turismo continue sendo tratado de forma cuidadosa e responsável pelas novas gerações. ${ }^{7}$

Metodologicamente, consiste no desenvolvimento de palestras aos professores do município, saídas técnicas, oficinas para os estudantes das escolas e a inserção de suas temáticas no currículo escolar. Segundo João ${ }^{8}$, professor da rede municipal, o projeto envolve a realização de diversas atividades nas escolas:

Neste projeto Pulando Janelas, nós trabalhamos o patrimônio, visto que nossa cidade é vista como a cidade mais italiana do Brasil, tem o reconhecimento por suas riquezas, pelo seu centro histórico que é rico pelas suas casas tombadas, alguns pontos turísticos que são muito relevantes aqui para o município, nosso patrimônio histórico e artístico nacional. A gente

\footnotetext{
${ }^{7}$ Fonte: http://www.serragaucha.com/pt/paginas/projetos. Acesso em: 10/07/2015

${ }^{8}$ Para preservar a identidade dos professores entrevistados, utilizaremos os pseudônimos João e Paula.
} 
desenvolve no Pulando Janelas atividades de incentivo e valorização do patrimônio material e do patrimônio imaterial e, dentro da escola, a gente promove algumas ações junto com o grupo de professores (João, professor).

A organização temática deste projeto favorece uma ambiguidade entre educação patrimonial e educação turística. No entanto, há uma predominância da dimensão econômica em relação aos demais elementos presentes na patrimonialização cultural. Pensando com David Harvey, parece-nos que a busca por rendimentos monopólicos condiciona a produção cultural neste contexto, ao mesmo tempo em que uma pedagogia da memória parece entrecruzar-se com certas expectativas de renda ou desenvolvimento turístico. A sequência do depoimento de João evidencia estas interfaces:

Neste ano, por exemplo, o foco é empreendedorismo. Nós temos uma turma de $8^{\circ}$ ano e uma turma de $4^{\circ}$ ano que pensaram e continuam pensando em produtos que são desenvolvidos no município e que a gente pode estar explorando muito mais, estar mostrando para outras pessoas este potencial, estas riquezas como um todo (João, professor).

Na continuidade, o professor nos oferece mais uma referência:

Uma professora de $8^{\circ}$ ano estava desenvolvendo um trabalho. Trabalhava a riqueza das cidades e falava sobre cidades criativas, ou seja, o que a gente desenvolve em nosso município com as riquezas, com os patrimônios que nós temos e o que pode ser feito. [...] Ainda está muito incutida a ideia de atraso como tombamento (João, professor).

A definição do processo de patrimonialização cultural ocorrido em Antônio Prado evidencia, no imaginário local, o binômio atraso/progresso. A dimensão econômica é predominante na reelaboração simbólica do lugar, onde cultura é latência de desenvolvimento econômico e as identificações culturais com a imigração italiana são recursos retóricos ao tombamento (PEIXOTO, 2004). Incide sobre esse argumento outro binômio - valorização e exploração do patrimônio - muito presente nos depoimentos dos professores quando comentam sobre as ações de educação patrimonial.

As escolas estão desenvolvendo trabalhos, atividades, ações, pensando neste conhecimento, neste reconhecimento, nesta conscientização, para se chegar a uma valorização e a uma exploração deste patrimônio (Paula, professora).

Cumpre destacarmos ainda a inexistência de uma política municipal de educação patrimonial, que realize ações sistemáticas e regulares acerca desta temática central à vida social em Antônio Prado. As ações promovidas são pouco sistemáticas e dependentes de projetos de atores individuais ou de agências de desenvolvimento regional. Como observa a 
professora Paula, "falando de escola, o trabalho é mais induzido pelos projetos". Segundo nossa informante,

Eu penso que este projeto Pulando Janelas veio como algo que motivou pra isto, sabe. Por que até então nós não tínhamos realmente nada, não se discutia este assunto dentro das escolas, se desenvolviam outros projetos, mas nenhum projeto voltado para a questão do turismo, para a questão da valorização do patrimônio que a gente tem (Paula, professora).

\section{Discussão final}

Por fim, faz-se necessário registrarmos que a educação patrimonial, muito mais que uma mera intervenção ou metodologia, configura um elemento fundamental nas elaborações e reelaborações simbólicas evidentes nos processos de patrimonialização cultural. Diversos são os interesses e objetivos sociais que se entrecruzam nestas dinâmicas.

As estratégias patrimonialistas de nossos dias procuram fundamentar a sua ação na salvaguarda exclusiva dos recursos materiais e culturais em risco de desaparecimento. Mas sabemos que como essa é uma retórica falaciosa. Os tempos de hoje são de manifesta inflação patrimonial e, enquanto tal, a patrimonialização serve também os propósitos do mercado e do turismo (FORTUNA, 2012, p. 25).

Diante destes usos da cultura e da patrimonialização cultural nas sociedades contemporâneas (YÚDICE, 2002; 2004; FORTUNA, 2012; SOVIK, 2014), a educação patrimonial assume novos contornos societários e engaja-se em múltiplos propósitos, convertendo-se em um (novo) objeto interdisciplinar para reflexões científicas e intelectuais nas Ciências Sociais (IBARRA; BONOMO; RAMÍREZ, 2014).

\section{Referências}

ABREU, Regina. Patrimonialização das diferenças e os novos sujeitos de direito coletivo no Brasil. In: TARDY, Cecile; DODEBEI, Vera. (Orgs.) Memória e novos patrimônios. Marseille: Open Edition Press, 2015. p. 67-93.

BUCHEBUAN, Terezinha. O. Os velhos casarões de Antônio Prado: processos culturais, patrimônio e conflito. 2010. Dissertação (Mestrado). Programa de Pós-Graduação em Letras, Cultura e Regionalidade. Universidade de Caxias do Sul, 2010.

CANCLINI, Néstor Garcia. Consumidores e Cidadãos: conflitos multiculturais da

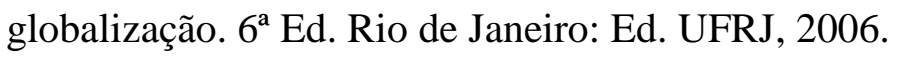

FEATHERSTONE, Mike. O desmanche da cultura: globalização, pós-modernismo e identidade. São Paulo: Studio Nobel/SESC, 1997. 
FORTUNA, Carlos. Património, turismo e emoção. Revista Crítica de Ciências Sociais, Coimbra,Portigal: v. 97, p. 23-40, 2012.

GIRON, Loraine Slomp. Colonos e fazendeiros: imigrantes italianos nos Campos de Cima da Serra. In: GIRON, Loraine Slomp. (Org.) Colonos e fazendeiros: imigrantes italianos nos campos de Vacaria. Porto Alegre: EST, 2001. p. 9-16.

; HEREDIA, Vania. História da Imigração Italiana no Rio Grande do Sul. Porto Alegre: EST, 2007.

IBARRA, Macarena; BONOMO, Umberto; RAMIREZ, Cecília. El patrimonio como objeto de estudio interdisciplinario. Reflexiones desde la educación formal chilena.Polis. Santiago, Chile: v. 13, n. 39, p. 373-391, 2014.

LEWGOY, Bernardo. Do velho ao antigo: etnografia do surgimento de um patrimônio. São Paulo, v. 5/6, p. 1-23, 1997.

LIPOVETSKY, Gilles; SERROY, Jean. A cultura-mundo: resposta a uma sociedade desorientada. São Paulo: Companhia das Letras, 2011.

MARTÍN-BARBERO, Jesús. Ofício de cartógrafo: travessias latino-americanas da comunicação na cultura. São Paulo: Loyola, 2004.

MARTINS, Pedro. Cabo-verdianos em Lisboa: manifestações expressivas e reconstrução identitária. Horizontes Antropológicos, Porto Alegre, n. 31, p. 241-269, 2009.

MEMÓRIA E PRESERVAÇÃO - Antônio Prado - RS. Brasília: IPHAN/Monumenta, 2009.

NORA, Pierre. Entre memória e história: a problemática dos lugares. Projeto História, São Paulo, n. 10, p. 7-28, 1993.

PEIXOTO, Paulo. A identidade como recurso metonímico dos processos de patrimonialização. Revista Crítica de Ciências Sociais, Coimbra, v. 70, p. 183-2014, 2004.

POLLAK, Michael. Memória, esquecimento, silêncio. Estudos Históricos, Rio de Janeiro, v. 2, n. 3, p. 3-15, 1989.

ROVEDA, Fernando. Memória \& Identidade: Antônio Prado, Patrimônio Histórico e Artístico Nacional. Caxias do Sul: Lorigraf, 2005.

SILVA, Rodrigo Manoel Dias da. Políticas socioculturais brasileiras e os interesses formativos do Programa Cultura Viva. Revista Brasileira de Estudos Pedagógicos, Brasília, v. 94, n. 236, p. 249-274, 2013.

Educação, cidadania e agenciamentos formativos nas políticas culturais brasileiras.

Educação \& Sociedade, Campinas, v. 35, n. 127, p. 397-415, 2014.

SOVIK, Liv. Os projetos culturais e seu significado social.Galáxia, São Paulo, n. 27, p. 172$182,2014$. 
VAN VELSEN, Jaap. A análise situacional e o método de estudo de caso detalhado. In: FELDMAN-BIANCO, Bela. (Org.) A Antropologia das sociedades contemporâneas. São Paulo: Global, 1987.

YÚDICE, George. La globalización y la nueva división internacional del trabajo cultural. In: LACARRIEU, Mónica; ÁLVAREZ, Marcelo. (Comp.) La (indi)gestión cultural: una cartografía de los procesos culturales contemporáneos. Buenos Aires: La Crujía, 2002. p. 1945.

A conveniência da cultura: usos da cultura na era global. Belo Horizonte: Ed. UFMG, 2004.

ARTIGO ENVIADO EM: 08/09/2015

ARTIGO ACEITO PARA PUBLICAÇÃO EM: 12/06/2016 